Article

\title{
The Multiscale Fluctuations of the Correlation between Oil Price and Wind Energy Stock
}

\author{
Shupei Huang ${ }^{1,2,3,4}$, Haizhong An 1,2,3,*, Xiangyun Gao ${ }^{1,2,3}$ and Meihui Jiang 1,2,3 \\ 1 School of Humanities and Economic Management, China University of Geosciences, Beijing, China; \\ hspburn@163.com (S.H.); gxy5669777@126.com (X.G.); jiangmh@cugb.edu.cn (M.J.) \\ 2 Key Laboratory of Carrying Capacity Assessment for Resource and Environment, \\ Ministry of Land and Resources, Beijing 100083, China \\ 3 Open Lab of Talents Evaluation, Ministry of Land and Resources, Beijing 100083, China \\ 4 Department of Science and Technology, Parthenope University of Naples, Centro Direzionale-Isola C4, \\ Napoli 80143, Italy \\ * Correspondence: ahz369@163.com; Tel.: +86-10-8232-3783; Fax: +86-10-8232-1783 \\ Academic Editor: Lin Lu \\ Received: 27 November 2015; Accepted: 26 May 2016; Published: 4 June 2016
}

\begin{abstract}
Wind energy is considered a clear and sustainable substitution for fossil fuel, and the stock index of the wind energy industry is closely related to the oil price fluctuation. Their relationship is characterized by multiscale and time-varying features based on a variety of stakeholders who have different objectives within various time horizons, which makes it difficult to identify the factor in which time scale could be the most influential one in the market. Aiming to explore the correlation between oil price and the wind energy stock index from the time-frequency domain in a dynamic perspective, we propose an algorithm combining the wavelet transform, complex network, and gray correlation analyses and choose the Brent oil price and the international securities exchange (ISE) global wind energy index from January 2006 to October 2015 in daily frequency as data sample. First, we define the multiscale conformation by a set of fluctuation information with different time horizons to represent the fluctuation status of the correlation of the oil-wind nexus rather than by a single original correlation value. Then, we transform the multiscale conformation evolution into a network model, and only 270 multiscale conformations and 710 transmissions could characterize 2451 data points. We find that only $30 \%$ of conformations and transmissions work as a backbone of the entire correlation series; through these major conformations, we identify that the main factor that could influence the oil-wind nexus are long-term components, such as policies, the status of the global economy and demand-supply issues. In addition, there is a clustering effect and transmissions among conformations that mainly happen inside clusters and rarely among clusters, which means the interaction of the oil-wind nexus is stable over a short period of time.
\end{abstract}

Keywords: wind energy; oil price; multiscale; complex network

\section{Introduction}

The green gas emissions and climate changes caused by fossil fuel consumption derive an urgent demand of the shift from traditional energy sources to renewable ones [1]. Among the developments of different renewable resources, wind energy attracts a huge body of concerns due to its long history and promising potential [2]. Being a clear and sustainable substitution for fossil fuel, there is significant evidence proves that fluctuations in the oil price closely relate to the performance of the wind energy industry, especially the linkage between oil price and the wind energy stock index [3]. Their relationships are explored by the Granger causality test, the asymmetric BEKK (named after Baba, Engle, Kraft, and Kroner), the copula, and models from the GARCH (Generalized Auto Regressive 
Conditional Heteroskedasticity) family in the entire sample period from a holistic perspective [4-8]. However, previous research has mainly focused on the time domain and has ignored the information from different time horizons. This multiscale information from a variety of time scales is hidden in the frequency domain, which are the main contributors of the nonstationary and nonlinearity of the financial time series [9]. Theoretically, oil price fluctuations could affect the wind energy stock from two perspectives-one is through the cash flows of companies in the future, and the other is through the discount of cash flow, such as exchange rate, interest rate, and monetary policy. Moreover, these two kinds of impacts from oil prices on the wind energy stock index may be distinguished in different time horizons [10]. Moreover, stakeholders involved in two markets have objectives with in different time horizons [11]. To be more specific, demand and supply factors are elasticated in the long term but is of rigidity in the short term, and financial investments mainly focus on short-term profit. Therefore, it is necessary to find out whether the relationship between the oil price and the wind energy stock index is dominated by which time horizon and the dynamic evolution of the determined multiscale information.

We aim to explore the multiscale fluctuation of the correlation between the oil price and the wind energy stock index in the joint time-frequency domain. Concerning the multiscale issue, the wavelet transform offers an effective solution. The main idea of the wavelet transform is to decompose the original time series into a variety of time horizons by transforming the time series as the function of time into the function of time and frequency [12-14]. Thus, with the wavelet transform, we can obtain more detailed information about the original time series in different time horizons. In addition, the wavelet transform can decompose the nonstationary time directly. Previous works that apply the wavelet transform to explore the fluctuation of oil price, stock markets, and their relationships from multiscale perspectives prove that wavelets can offer a deeper understanding to the fluctuations and interactions of multiple financial markets [15-23].

Moreover, the interaction between the oil price and the wind stock index is time varying, which means the oil-wind stock nexus changes over time [3]. However, most existing researches examine their correlation in an average manner, which masks varieties and diversities. Hence, uncovering features of the correlation evolution with changes over time could offer more reference for decision-making, and considering potential upsides and downward trends [24]. Furthermore, the complex network analysis is an ideal choice for discovering the dynamic evolution features of the time series. The complex network analysis treats the complicated system as a network and characterizes the network by its structural features. Time series is the signal generated by the economical and financial systems. Transforming a time series into a network model could offer novel and structural observations to the system quantitatively. Works in multiple disciplines, the financial field in particular, prove that the complex network could explore the time series effectively and validly [25-34].

Aiming to examine the fluctuation of the correlation of the oil price and the wind energy stock index, we propose a novel algorithm combining the wavelet transform, the complex network, and gray correlation analyses. First, we implement the gray correlation to estimate the correlation between the oil price and the wind energy stock index in a point-to-point way. Then, we decompose their gray correlation series into a time-frequency domain and define the multiscale conformation for each time point to express the fluctuation status of the correlation of the oil-wind nexus using a set of data from different time horizons rather than using the original single value. We transform the time series into a network model by taking the multiscale conformation for a time point as a node and the transmissions among them over time as edges, and then characterize the network by its structural features. By doing so, we offer a comprehensive observation to the interaction between the oil price and the wind energy stock index from both time and frequency perspectives. Specifically, the frequency aspect could be helpful in identifying the scales from which the main contributors come. The evolution over time could identify fluctuation features of the main influential time scale of interactions across financial markets. 


\section{Data and Algorithm Description}

\subsection{Data Description}

Aiming to explore the multiscale conformation of the correlation between the oil price and wind energy stock, we choose the Brent oil price (Brent) as the proxy for the international oil price because over half of the oil markets all over the world choose it as the benchmark oil price and, due to the shale gas booming in the US and the domestic issues of refining capacity and oil pipelines, the WTI has been recently diversified with the Brent oil price and tends to reflect the domestic oil market in the US rather than the international price level [35]. The ISE global wind energy index (wind) is used to display fluctuations in the wind energy market because this index includes major public wind energy companies around the world in which their products or services are playing vital role in the wind energy industry. We sample the wind stock index and Brent price in the period from January 2006 to October 2015 in daily frequency.

To show trends of the Brent oil price and the wind energy stock index more clearly, we normalized the original price series (Figure 1). Original prices of the wind stock index and the Brent have similar trends before 2010; they increased and went down together. Before August 2008, the wind stock index went up with the oil price, which indicates a higher elasticity of substitutions of the wind energy, and the rapid increase of the oil price promotes the development of the world energy industry. During the financial crisis period, the entire economy was involved in a downslide, and all commodity markets including the crude oil and the wind energy industry experienced sharp decreases. After the financial crisis, with the recovery of the world economy, the demand of the oil and wind energy went up. However, after 2010, the oil price kept going up with fluctuations, but the wind industry hovered at a low level. Compared to fossil fuel, renewable energy such as wind energy generally entails high costs to install and maintain and are not convenient to store. Hence, in the recovery period of the world economy, fossil fuel still took the dominant place. In 2015, the wind and Brent fluctuated around similar price level after the Brent oil price dropped dramatically in 2014. The dramatic drop of the oil price made the prices in the energy industry decrease, which encouraged energy companies that have more capital to invest in new energy fields.
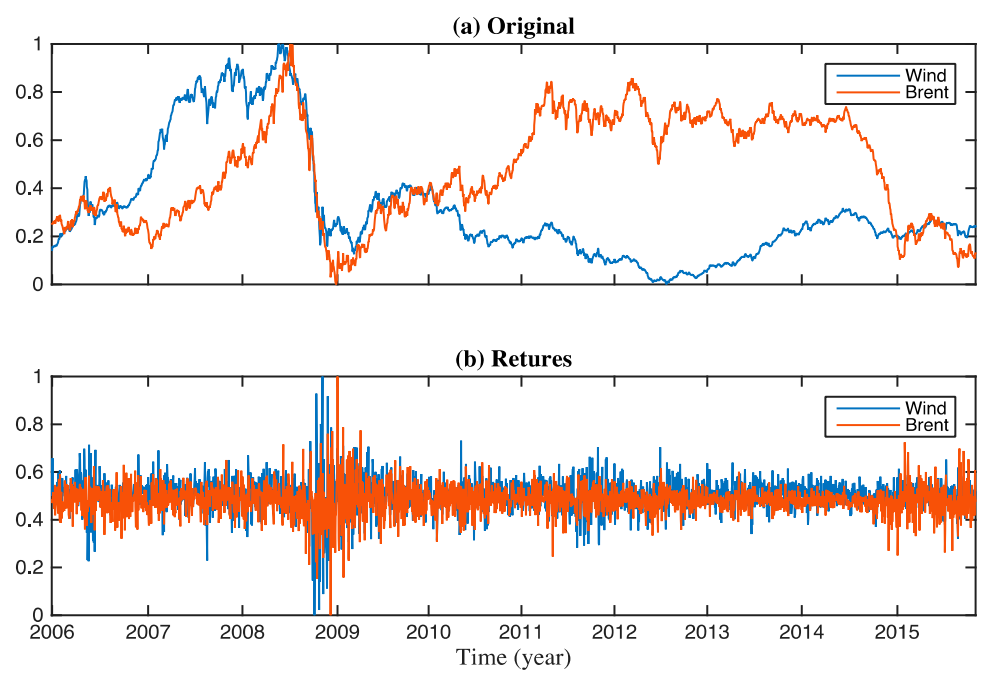

Figure 1. Original prices and returns of the Brent oil price and wind energy stock index. (a) plots the original price of Brent oil price and the wind energy stock index, and (b) indicates the returns of Brent oil price and the wind energy stock index.

We transformed the original Brent and wind prices into a logarithmic first difference (Figure 1b), and their logarithmic returns fluctuate highly, particularly around 2009. However, through the 
logarithmic returns of the oil price and wind index, it is difficult to identify market features. Then, we move on to further explorations with an integrated research framework.

\subsection{Algorithms}

Being different from previous methods, mainly focusing on the time or frequency domain separately, we proposed an integrated research framework combining gray correlation analysis, wavelet transform, and network analysis, which could offer a more comprehensive manner to observe the relationship between the oil price and the wind energy stock index quantitatively in both time and frequency dimensions. Specifically, from the point of view of dynamic evolution over time, we could find major interaction statuses and fluctuation features between the oil price and the wind energy stock index. Considering the frequency aspect, it will be helpful to identify the most influential time scale to the oil-wind energy nexus.

Generally, the wavelet transform is used to decompose the original time series, and further measurements are then carried out based on the decomposed series corresponding to different time horizons. As mentioned above, in reality, there are different stakeholders associated with the crude oil and wind energy markets, and they have objectives rooted within different time horizons. All of these multiscale factors working together form the entire interactions between the oil markets and the wind energy stock market. In other words, the relationship between the oil price and the wind energy stock index are composed. Through the decomposition of the original time series, it is possible to determine the features of different frequency components separately but fail to identify the influence of these components on the entire market interactions that appear in the real markets. Hence, we decompose the correlation series (the entire markets interaction) and try to determine which main frequency component can exert more influence on the entire market. Then, through identifying major factors in the corresponding time-scale, we can offer more practical suggestions. Specifically, if the long-term component of the correlation series is the main contributor, we infer that the oil price affects the wind energy market mainly through a cash flow discount, such as exchange rate, interest rate, and policy issues in the long run.

\subsubsection{Co-Movement in Time Domain}

Concerning two financial time series of Brent and wind energy returns that have nonlinear and nonstationary features, we estimate their dynamical co-movement with gray correlation analysis. Gray correlation analysis evaluates the similarity between two time series in a point-to-point manner, which can also demonstrate their influence on each other [36,37]. Since the gray correlation is based on the geometric distance between two series, there is no specific requirement for the time series and could estimate the correlation in a dynamic way. The calculation equation could be written as follows:

$$
\gamma\left(x_{0}(k), x_{i}(k)\right)=\frac{\min _{i} \min _{k}\left|x_{0}(k)-x_{i}(k)\right|+\varepsilon \min _{i} \min _{k}\left|x_{0}(k)-x_{i}(k)\right|}{\left|x_{0}(k)-x_{i}(k)\right|+\varepsilon \min _{i} \min _{k}\left|x_{0}(k)-x_{i}(k)\right|},
$$

where $\gamma\left(x_{0}(k), x_{i}(k)\right)$ display the correlation coefficients between two given time series for each time point. $\varepsilon$ is the adjusted coefficient that can control the difference of the calculation of the gray correlation coefficients. A $\varepsilon$-value of 0.5 is a reasonable choice for the economical and financial time series [38].

\subsubsection{Decomposition into the Time-Frequency Domain}

Because the hidden information in the time-frequency domain is the main contributor to the nonlinear and nonstationary of the financial time series, we use the continuous wavelet transform to decompose the dynamic correlation series of Brent-wind into the time-frequency domain to display their fluctuations with changes in time and frequency. The main idea of the continuous wavelet transform is that using different resolutions to observe the original time and the various resolutions could focus on the information in different time horizons [39]. The calculation of the continuous 
wavelet transform could be implemented by transforming the original time series as the function of time into the function of time and scale with the wavelet. Hence, there are two parameters for the wavelet, namely location $(\mathrm{u})$ and scale (s). The location parameter s could track changes in the time domain, while the scale parameter $\mathrm{u}$ could determine the resolution by stretching or compacting the wavelet.

$$
\psi_{u, s}=\frac{1}{\sqrt{s}} \psi\left(\frac{t-u}{s}\right) .
$$

There are a family of wavelets, among which we choose the Morlet wavelet with $\omega_{0}=6$ [40], which has a good balance between the time and scale and could be represented as follows:

$$
\psi_{0}(\eta)=\pi^{-1 / 4} e^{i \omega_{0} \eta} e^{-1 / 2 \eta^{2}}
$$

The convolution of the original time series and the wavelet function, we can obtain the continuous wavelet transform as

$$
W_{X}(u, s)=\int_{-\infty}^{\infty} \frac{1}{\sqrt{s}} \overline{\psi\left(\frac{t-s}{s}\right) d t}
$$

In the continuous wavelet transform, we can obtain the amplitude and its square. The square of the amplitude is considered the wavelet power spectrum and can demonstrate the energy allocation of the original time series in the time-frequency domain. In other words, we can distinguish the fluctuation extent of the correlation series in different times and frequencies with the wavelet power spectrum. The wavelet transform actually results in a $n^{*} m$ matrix, where $n$ and $m$ correspond to the number of frequency bands and the number of time points, respectively.

\subsubsection{Construction of the Multiscale Conformation Evolution Network}

To explore the multiscale fluctuation of the Brent-wind interaction with time, we transform its wavelet power spectrum into a network model.

Step 1. The discretization of the wavelet power spectrum. The wavelet power spectrum shows a clearer picture of the fluctuation of the correlation of Brent-wind in detail. The frequency band of the wavelet power spectrum is continuous and rings from 2 to 512 days. Here, we choose the frequency band of 2 days, 4 days, 8 days, 16 days, 32 days, 64 days, 128 days, 256 days, and 512 days as the backbone to stand for the entire continuous frequency band according to the discretization method of the discrete wavelet transform. As mentioned, the wavelet power spectrum is a $n^{*} m$ matrix, where $n$ is the number of frequency bands that constitute the continuous frequency band, and $\mathrm{m}$ is the number of data points. After the discretization we obtain a new matrix, the size of which is $9^{*} \mathrm{~m}$. We normalize the discretized wavelet power spectrum matrix through the logarithmic transform.

Step 2. The definition of the multiscale conformation. First, we divide the values of the discretized wavelet power spectrum into four levels according to its maximum and minimum and divide the value ranges from the minimum to the maximum into four equal intervals. We also use L1, L2, L3, and L4, which mean the fluctuation is very weak, weak, high, and very high, respectively. For each time point, there are nine components from different time horizons, and the combination of them can determine the status of the original Brent-wind correlation. Here, we define the multiscale combination of nine time scales at one time point as the multiscale conformation.

Step 3. Constructing an evolution network for the multiscale conformations. Taking multiscale conformations as nodes, transmissions among them as edges, we transform the series of multiscale conformations into a network. Details are shown in Figure 2. Among nodes and edges, transmissions between two types of multiscale conformations appear repetitively; therefore, we take the $\mathrm{n}$ umber at which these edges appear as its weight. 


\begin{tabular}{|c|c|c|c|c|c|c|c|}
\hline Frequency & $\mathrm{t} 1$ & & $\mathrm{t} 2$ & $\mathrm{t} 3$ & $\mathrm{t} 4$ & $\cdots$ & tk \\
\hline 2 days & L4 & & $\mathrm{L} 4$ & L4 & $\mathrm{L} 4$ & & L2 \\
\hline 4 days & L4 & & $\mathrm{L} 4$ & L4 & L3 & & L3 \\
\hline 8 days & L3 & & L3 & L4 & $\mathrm{L} 4$ & & L3 \\
\hline 16 days & L4 & & $\mathrm{L} 4$ & L4 & $\mathrm{L} 4$ & & L3 \\
\hline 32 days & L3 & $\longrightarrow$ & L3 & L3 & L3 & $\cdots$ & L3 \\
\hline 64 days & L4 & i & $\mathrm{L} 4$ & L4 & L4 & & L4 \\
\hline 128 days & L4 & I & $\mathrm{L} 4$ & L4 & L4 & & L4 \\
\hline 256 days & L3 & i & L3 & L3 & L3 & & $\mathrm{L} 4$ \\
\hline 512 days & L4 & i & $\mathrm{L} 4$ & L4 & $\mathrm{L} 4$ & & L4 \\
\hline & $\begin{array}{c}1 \\
1 \\
1 \\
\text { Mul }\end{array}$ & \multicolumn{6}{|c|}{$\begin{array}{l}\downarrow \\
\text { Transmission (Edge) }\end{array}$} \\
\hline
\end{tabular}

Figure 2. The construction of the evolution network for the multiscale conformations.

\section{Empirical Results and Discussion}

\subsection{Fluctuations of Correlations of Brent-wind in the Time Domain}

Generally, the gray correlation coefficients between wind and Brent are above 0.6 (Figure 3), which means their correlation is relative high, and the fluctuation of the oil price could trigger the shocks in the global wind industry. However, fluctuations in their correlation coefficients series are extremely high, and it is difficult to characterize the co-movement between wind and Brent returns in a precise manner. As mentioned above, the interaction between the oil price and wind stock index has multiscale features and their complicated behaviors are decided by the market components from different time horizons. Hence, observing the Brent-wind interaction from a multiscale perspective rather than only from the time domain could help to attain a deeper understanding. More specifically, through the information from the multiple time scale, we are capable of distinguishing the fluctuation of the Brent-wind in which the time scale is dominant and plays a more important role.

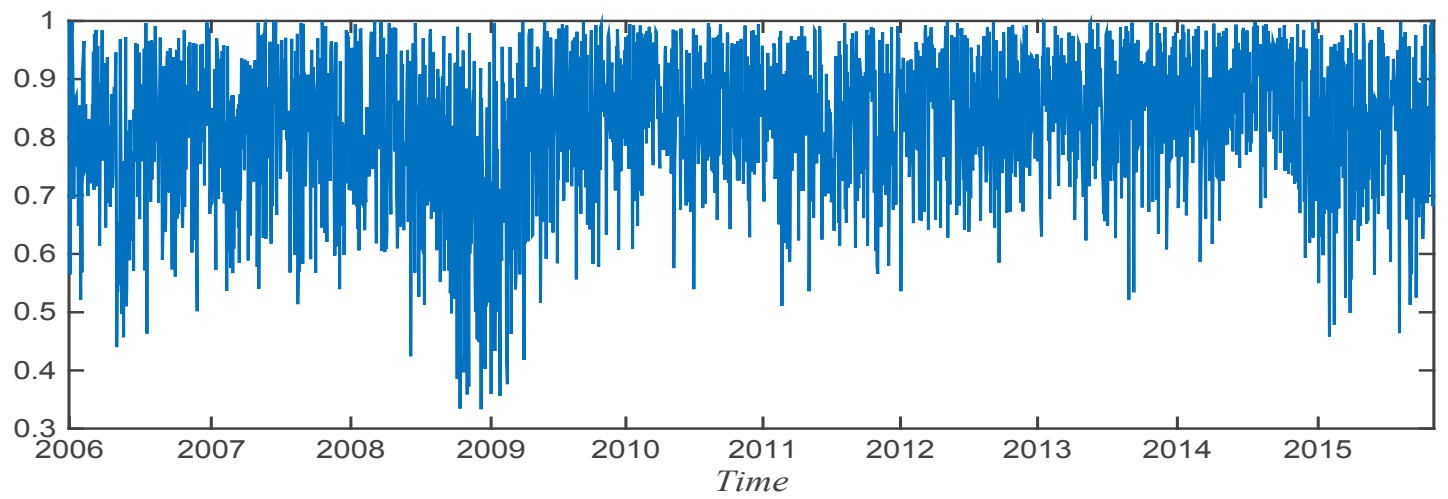

Figure 3. The gray correlation coefficients of the Brent oil price and the wind energy stock price.

\subsection{Decomposition in Time-Frequency Domain}

With the continuous wavelet transform, we could obtain the wavelet power spectrum, which could demonstrate the energy allocation of the Gray correlation series of the Brent-wind nexus with changes of time and frequency (Figure 4). The wavelet power spectrum is visible, and the horizontal 
and vertical axes depict the time and frequency information, respectively. Shadowed areas on the left and right sides of the figure are regions affected by the boundary effect. We used a warm color and a solid black line to demarcate regions in which the fluctuation highly corresponds to certain time period and frequency band. For instance, from 2007 to 2009, in the frequency band of 128-512 days, the color of this area is yellow and circled by a solid black line, which means the fluctuation of the gray correlation in a time period from 500 to 12,500 is mainly decided by the components in the long term (frequency band of 128-512 days). This indicates that the relationship between the wind industry and oil price are mainly determined by long-term factors. In the high-frequency band (4-16 days), there also tiny areas circled by the black line, but their durations are especially short, which could mean that the market expectation in wind energy caused by the oil price fluctuations is not influential and will quickly peter out. Hence, the short-term fluctuations may be due to the fact that market expectations are short-lived, while fluctuations in the long term could last for a relevant long time period.

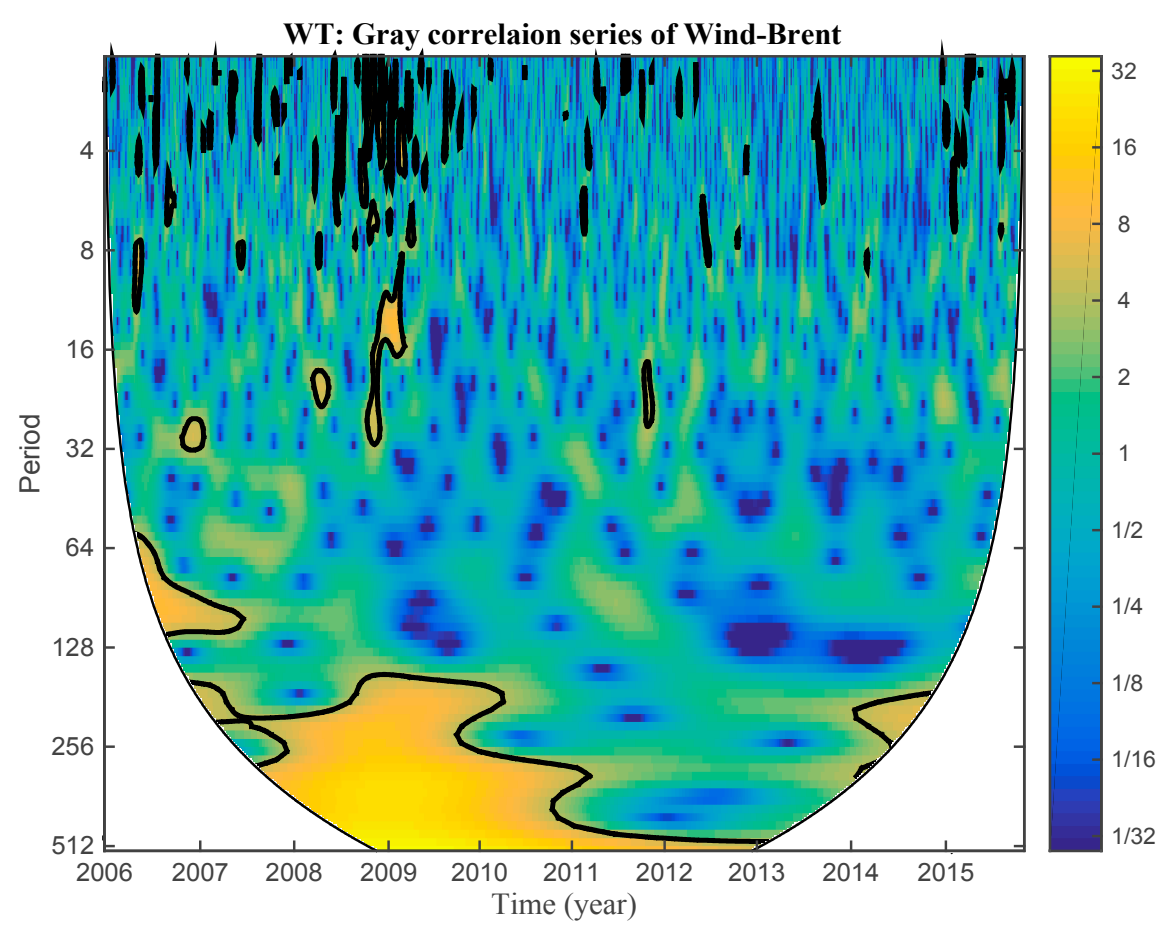

Figure 4. The wavelet power spectrum of the gray correlation series of the Brent-wind.

\subsection{Construction of the Evolution Network}

The wavelet power spectrum has a continuous frequency band, so we distinguish the continuous one into nine separate frequency bands, namely 2, 4, 8, 16, 32, 64, 128, 256, and 512 days. In Figure 5, it is obvious that the magnitude of the frequency components of the correlation coefficients series increases with the length of frequency band. Then, we transform a $n^{*} \mathrm{~m}$ wavelet power spectrum matrix into a $9^{*} \mathrm{~m}$ discrete wavelet power spectrum matrix. By normalizing the discrete matrix with a logarithmic transform, we obtain a maximum of -0.4 and a minimum of -7.38 . Dividing the range from -7.38 to -0.4 into four sub-regions corresponds to four fluctuation levels as follows:

$$
\text { fluctuation level }=\left\{\begin{array}{l}
\text { L1, wavelet power value } \in[-7.38,-5.63) \\
\text { L2, wavelet power value } \in[-5.63,-3.89) \\
\text { L3, wavelet power value } \in[-3.89,-2.14) \\
\text { L4, wavelet power value } \in[-2.14,-0.40]
\end{array}\right.
$$




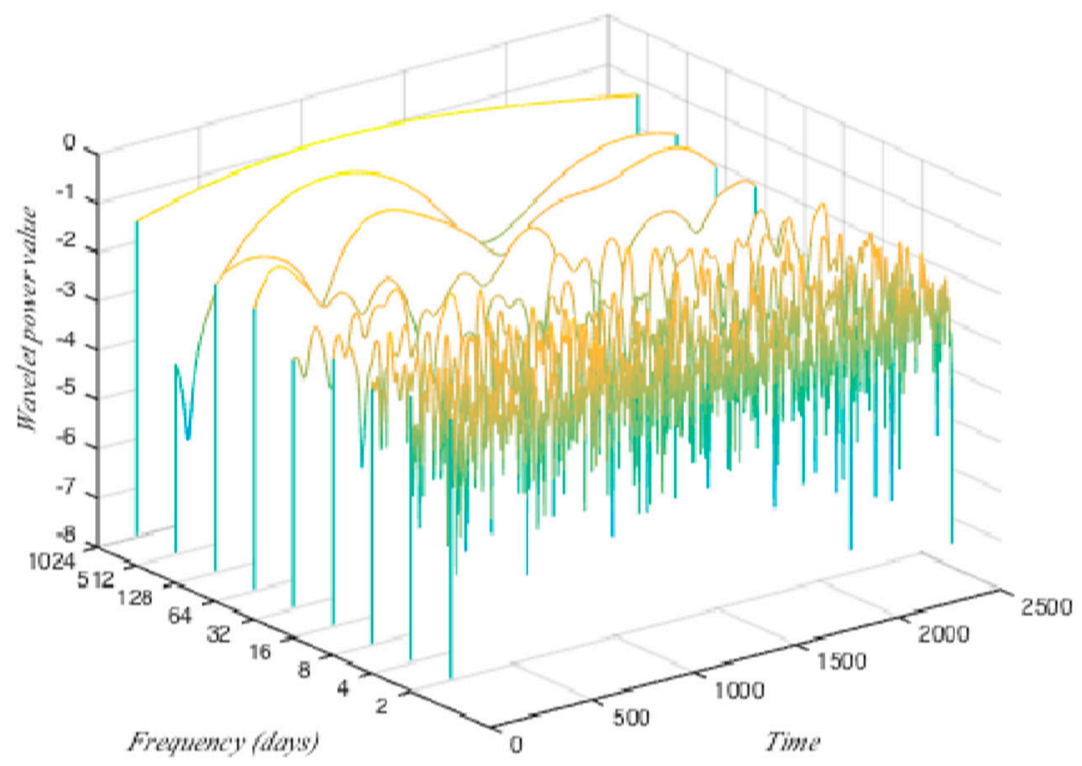

Figure 5. The discretization of the wavelet power spectrum.

Combining nine frequency components from different time horizons at each time point to obtain the multiscale conformations. Multiscale conformations at all time points form a sequence. We transform the multiscale conformation sequence evolving with time into a directed and weighted network by taking conformations as nodes and transmissions as edges (Figure 6). There should be 2451 multiscale conformations for every 2451 data points; however, there are only 270 conformations and 710 edges because of the repetitiveness of the multiscale conformations. The size of nodes is identified by the out-degree; when one node transfers to a large number of nodes, it has a large out-degree and large size. Each edge has its own weight that is decided by the frequency of the given edges appearing among the total transmissions. In addition, nodes are marked by different colors, which means nodes belong to different clusters. More details will be given in a later section.

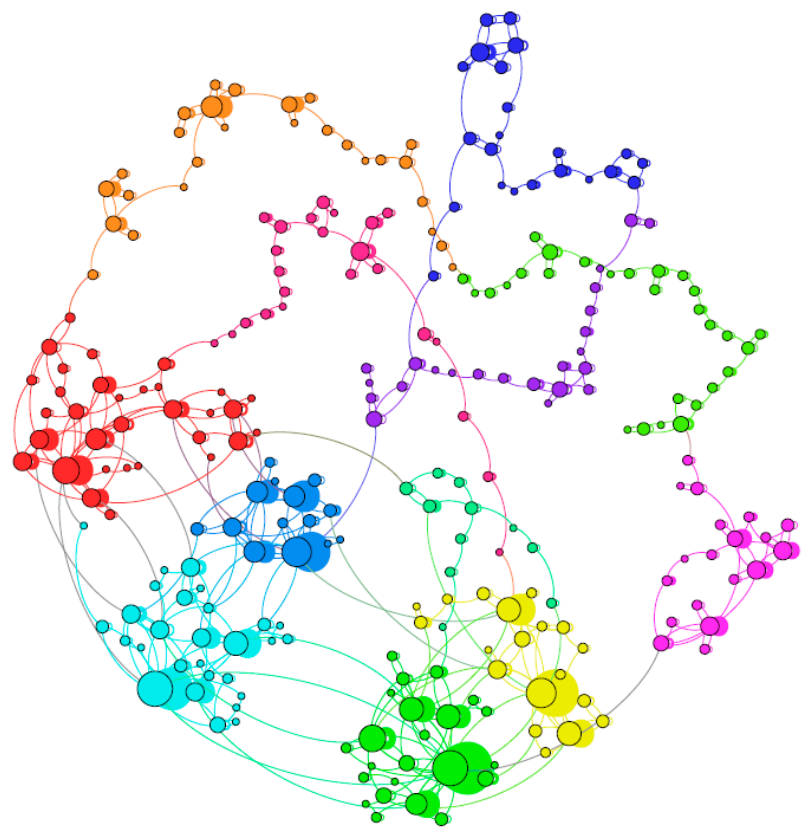

Figure 6. The evolution network of multiscale conformations of Brent-wind. 


\subsection{Evolution Features Analyses}

\subsubsection{Major Conformations and Transmissions}

In the evolution network of multiscale conformations, do some conformations play a more vital role than others? To answer this question, we introduce the index of a weighted out-degree that depicts the frequency of one given transmission from one conformation among all transmissions. The weighted out-degree of one multiscale conformation could be as follows:

$$
w_{i}^{o u t}=\sum_{j \in N_{i}} w_{i j},
$$

where $N_{i}$ represents the number of neighbors shared by the conformation $w_{i}$, and $w_{j}$ represents the weight between conformation $w_{i}$ and $w_{j}$. Figure 5 depicts features of the weighted out-degree and we find an $80.12 \%$ transmission occur among $31.85 \%$ of the total conformations (Figure $7 a$ ). In addition, the distribution of the weighted out-degree follows the low power distribution $p\left(w^{\text {out }}\right) \sim w^{\text {out }-\gamma}$ (Figure $7 b$ ), which also demonstrates that a small amount of multiscale conformations is more vital than others.
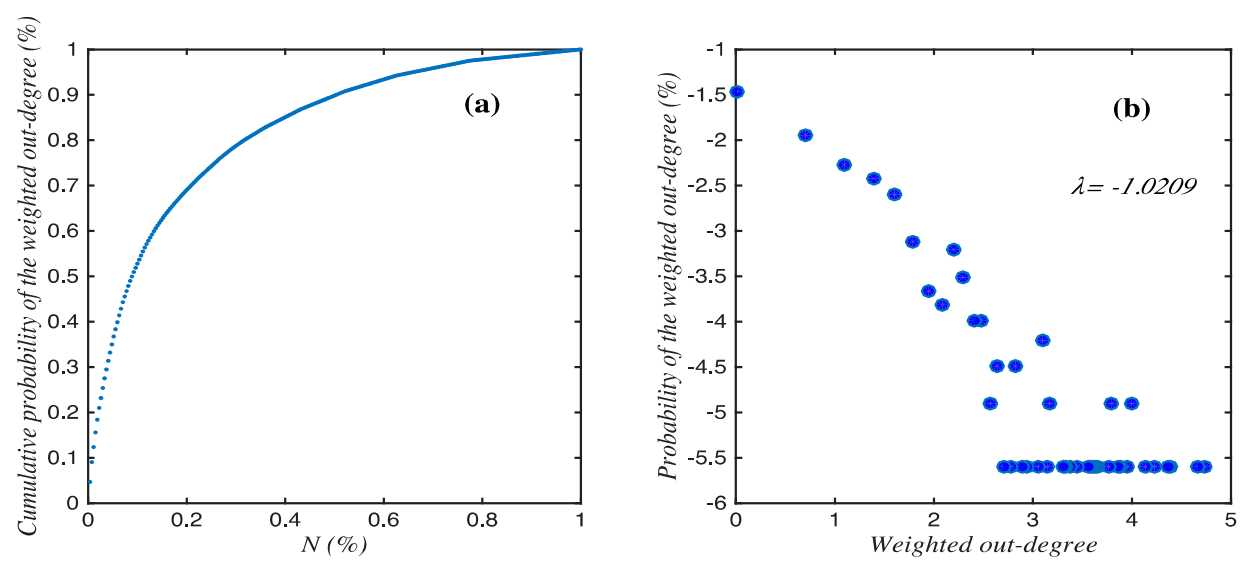

Figure 7. Distributions of the weighted out-degree of node. (a) Cumulative distribution of the weighted out-degree of the node (sorted by the value of the weighted out-degree of the nodes in descending order, $n=1,2, \ldots, 270$ ). (b) Double-logarithmic plot between the weighted out-degree of node and the probability of the weighted out-degree.

In Table 1, we list the top 10 major multiscale conformations ranking by the weighted out-degree. The accumulation percentage of their weighted out-degree accounts for around $30 \%$ of the total number. The attractive point is that the last three elements of each multiscale conformation are L4, which means that the entire correlation between the Brent oil price and the wind stock index is determined by the long-term components from the frequency bands of 128, 256, and 512 days. Generally, factors activated in the long term are associated with demand-supply, policy, and the economy circle. These factors are the main contributors of correlations between oil price and the wind energy stock index, which could be led by the inherent feature of the wind industry. In reality, wind energy is mainly used as distributed energy and the investment is high, and the main challenges are stability and storage, of which development requires subsidization and the promotion of new policy. Therefore, oil price shocks driven by these long-term factors tend to trigger the co-movements of the wind energy industry.

Currently, the world economy is in a downturn, and the supply of oil dramatically exceeds the demand, which indicates that the situation could be considered a long-term factor. Therefore, now is a good time to promote the development of the wind energy industry. The low price level of fossil fuel lowers the cost of relative energy industries, enabling investment in new energy fields. Moreover, the investment in a new energy industry could help the economy to recover. 
Table 1. The top 10 multiscale conformations ranked in order of the weighted out-degree.

\begin{tabular}{cccc}
\hline No. & Conformations & Weighted Out-Degree & $\begin{array}{c}\text { Percentage (\%) Accounts for } \\
\text { Total Weighted Out-Degree }\end{array}$ \\
\hline 1 & $\mathrm{~L}_{3} \mathrm{~L}_{3} \mathrm{~L}_{3} \mathrm{~L}_{3} \mathrm{~L}_{3} \mathrm{~L}_{3} \mathrm{~L}_{4} \mathrm{~L}_{4} \mathrm{~L}_{4}$ & 649 & 4.69 \\
2 & $\mathrm{~L}_{3} \mathrm{~L}_{3} \mathrm{~L}_{3} \mathrm{~L}_{4} \mathrm{~L}_{3} \mathrm{~L}_{3} \mathrm{~L}_{4} \mathrm{~L}_{4} \mathrm{~L}_{4}$ & 291 & 4.37 \\
3 & $\mathrm{~L}_{3} \mathrm{~L}_{3} \mathrm{~L}_{3} \mathrm{~L}_{3} \mathrm{~L}_{3} \mathrm{~L}_{4} \mathrm{~L}_{4} \mathrm{~L}_{4} \mathrm{~L}_{4}$ & 228 & 3.31 \\
4 & $\mathrm{~L}_{3} \mathrm{~L}_{3} \mathrm{~L}_{4} \mathrm{~L}_{4} \mathrm{~L}_{3} \mathrm{~L}_{4} \mathrm{~L}_{4} \mathrm{~L}_{4} \mathrm{~L}_{4}$ & 152 & 3.22 \\
5 & $\mathrm{~L}_{3} \mathrm{~L}_{3} \mathrm{~L}_{3} \mathrm{~L}_{4} \mathrm{~L}_{3} \mathrm{~L}_{4} \mathrm{~L}_{4} \mathrm{~L}_{4} \mathrm{~L}_{4}$ & 151 & 2.82 \\
6 & $\mathrm{~L}_{3} \mathrm{~L}_{3} \mathrm{~L}_{4} \mathrm{~L}_{4} \mathrm{~L}_{3} \mathrm{~L}_{3} \mathrm{~L}_{4} \mathrm{~L}_{4} \mathrm{~L}_{4}$ & 149 & 2.57 \\
7 & $\mathrm{~L}_{3} \mathrm{~L}_{3} \mathrm{~L}_{3} \mathrm{~L}_{3} \mathrm{~L}_{4} \mathrm{~L}_{4} \mathrm{~L}_{4} \mathrm{~L}_{4} \mathrm{~L}_{4}$ & 115 & 2.20 \\
8 & $\mathrm{~L}_{3} \mathrm{~L}_{4} \mathrm{~L}_{3} \mathrm{~L}_{3} \mathrm{~L}_{3} \mathrm{~L}_{3} \mathrm{~L}_{4} \mathrm{~L}_{4} \mathrm{~L}_{4}$ & 101 & 2.20 \\
9 & $\mathrm{~L}_{3} \mathrm{~L}_{3} \mathrm{~L}_{4} \mathrm{~L}_{3} \mathrm{~L}_{3} \mathrm{~L}_{4} \mathrm{~L}_{4} \mathrm{~L}_{4} \mathrm{~L}_{4}$ & 99 & 2.12 \\
10 & $\mathrm{~L}_{3} \mathrm{~L}_{3} \mathrm{~L}_{4} \mathrm{~L}_{3} \mathrm{~L}_{3} \mathrm{~L}_{3} \mathrm{~L}_{4} \mathrm{~L}_{4} \mathrm{~L}_{4}$ & 99 & 1.96 \\
\hline
\end{tabular}

\subsubsection{The Clustering Effect}

In the multiscale conformation evolution network, the average transmission path between the two conformations is 19.467 , which means that the transmission from one multiscale conformation to another one needs to pass 20 conformations on average. Thus, transmissions among conformations are not very easy. However, there are some multiscale conformations and transmission paths among them that are below the average value, which means transmissions among these conformations are much easier. Thus, there may be a clustering effect in the multiscale conformation evolution network, which means transmissions among some conformations are easy, while some conformations will be separated without the connection by other conformations.

We found that the whole multiscale conformation evolution network could be separated into 12 clusters and identified with numbers from 1 to 12 (the detail of the algorithm can be seen in [41]). Their sizes range from 11 to 32 of conformations. Inside the cluster, multiscale conformations within the same cluster are strongly linked, whereas transmissions among conformations in different clusters are more difficult. Figure 8 demonstrates transmissions between clusters, and a warmer color means more transmissions. It is obvious that nearly all transmissions occur inside clusters and the transmissions among clusters are nearly zero. Hence, in a short period, the interaction between the oil price and wind energy stock index is stable since the transmission of conformations mainly occur among small amounts of conformations, which could be is in line with the fact that the interaction between the oil price and the wind energy stock index is determined mainly by the long-term components. For instance, before the financial crisis, the high oil price, the booming development of the world economy, and the increasing environmental concerns were the main long-term factors driving the wind energy market. During the financial crisis and post-crisis periods, the downturn of the economy dominated the development of the wind industry. Currently, due to low commodity prices, such as oil and coal prices, the wind energy industry began to boom. 


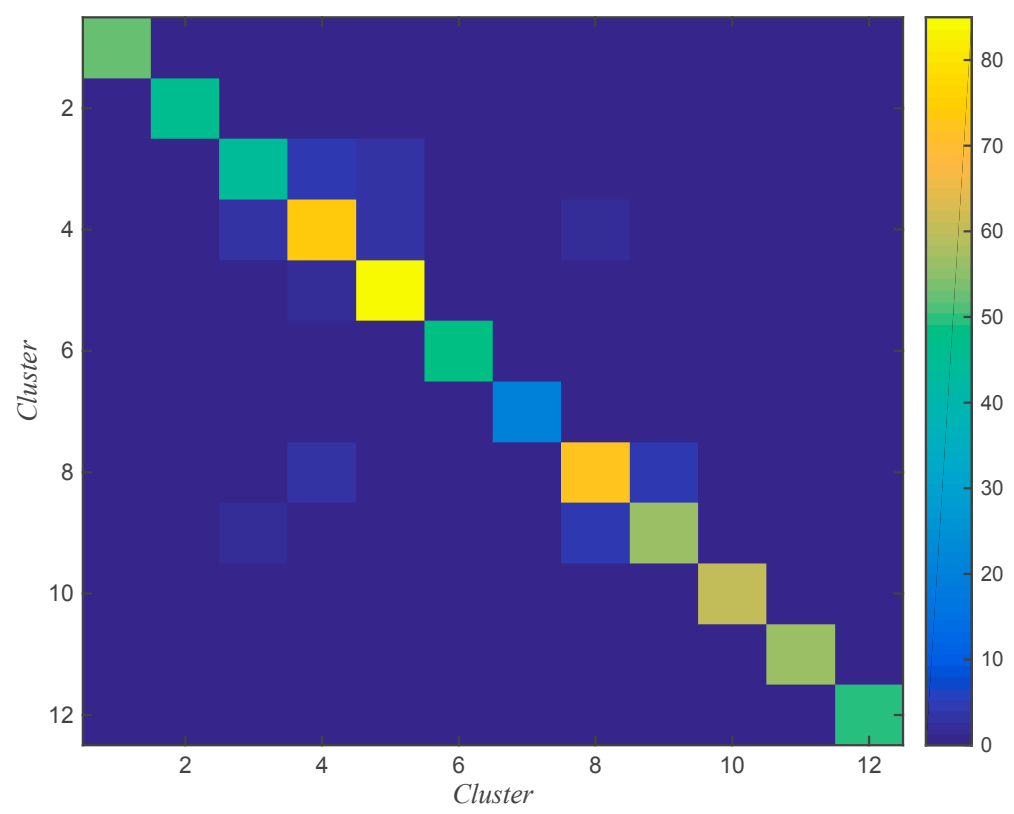

Figure 8. The transmission matrix among clusters.

The evolution of the cluster ID number over time is depicted in Figure 9. Different clusters divide the evolution of the multiscale conformation into different short periods. In one period, transmissions are limited to one specific cluster. Because the transmission between some clusters is 0 , when the evolution of multiscale conformation transmits from one cluster to another, only some specific clusters could possibly be the next one. For instance, Cluster 1 only involves transmissions inside itself and with Cluster 2. Thus, when the current conformation is from Cluster 1, the next conformation will be from Clusters 1 or 2 with high possibility.

The evolution of the cluster ID proves our inference that each cluster lasts for a short period. Before the financial crisis, the main cluster ID was around 4 and shifted to around 9 in the post-crisis period until 2014. After 2014, the major clusters are mainly around 8 or 2 . Through the transmission matrix in Figure 8, we can infer that the correlation between oil price and the wind energy stock presents a high possibility of hovering in Cluster 2 or transferring into Cluster 3, which means that the influence of the world economy downturn and low oil price could last for a period This should be considered fully before the wind energy industry is promoted.

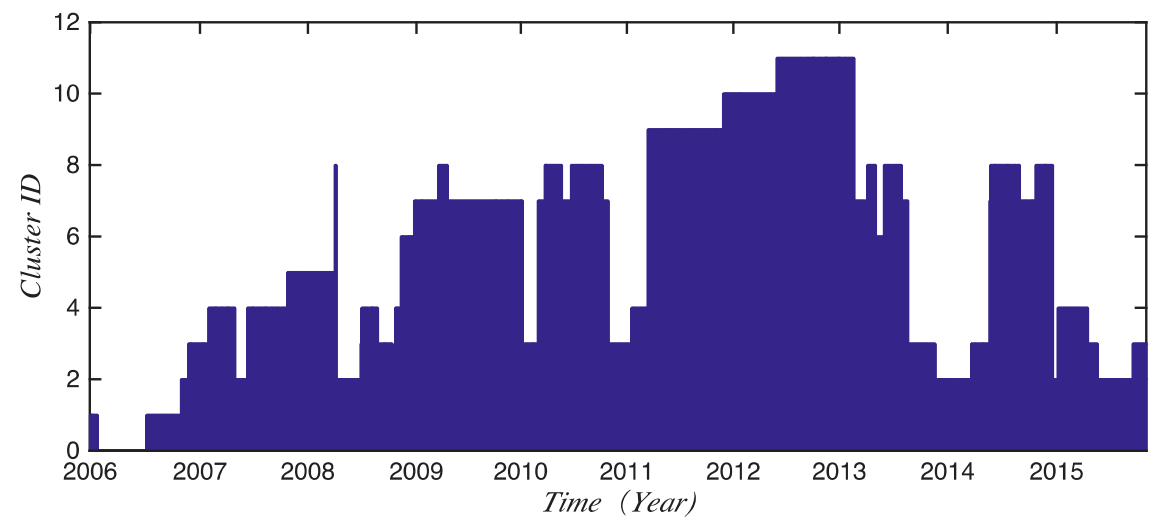

Figure 9. The evolution of the cluster ID of the multiscale conformations. 


\section{Conclusions}

The co-movement of the Brent-wind interaction behaves in an extremely complicated manner in the time domain, which might be triggered by the hidden multiscale information from the time-frequency domain. Aiming to explore the multiscale fluctuation of the interaction of the Brent-wind nexus, we proposed an algorithm that integrates gray correlation analysis, the wavelet power spectrum, and the complex network and chose the Brent oil price and wind energy stock index from January 2006 to October 2015 in daily frequency as the sample data.

Through transforming the correlation series into the time-frequency domain and constructing a multiscale conformation evolution network, we characterized 2451 data points by 270 multiscale conformations and 710 transmissions. Among these multiscale conformations, only $30 \%$ of whose transmissions undertake $80 \%$ of all transmissions, could be considered as decisive contributors to the Brent-wind interaction. Through major multiscale conformations, we identify that the main factors influencing the interaction between oil price and the wind energy stock markets are long-term components, such as demand-supply, policy, and the global economy situation. Therefore, promoting the wind energy industry to develop sustainably should pay more attention to long-term stable policies and subsidies.

In addition, the multiscale conformation evolution network shows a clustering effect and could be separated into 12 clusters. Specifically, transmissions mainly occur inside the same cluster, while transmissions among clusters rarely happen. Currently, the dominating factor of the interaction between oil price and the wind energy industry is the low oil price, which will last for a period of time. Therefore, it is good time to promote the development of the wind industry.

We characterize the Brent-wind nexus with its structural features of the multiscale conformation evolution network, which offer novel and detailed perspectives to understanding the financial cross-market interaction. Indeed, there are more factors involved in Brent-wind, such as other renewable energy markets and the coal market, and we will explore them in further research. In additional, in this paper we just find out the possible factors relate with the long-term components. The future study could focus on the contribution of specific factors to the oil-wind energy nexus.

Acknowledgments: We acknowledge four anonymous reviewers, whose valuable suggestions were helpful for us in improving the quality of the paper. This research was partially supported by the Science and Technology Innovation Fund of the China University of Geosciences (Beijing) (Grant No. 51223229), the China Geological Survey (Grant No. 2015YQKYQ0403), and Fundamental Research Funds for the Central Universities (Grant No. 2-9-2015-303).

Author Contributions: Haizhong An and Shupei Huang conceived and designed the experiments; Shupei Huang and Xiangyun Gao performed the experiments; Shupei Huang and Meihui Jiang analyzed the data; Shupei Huang wrote the paper.

Conflicts of Interest: The authors declare no conflict of interest.

\section{References}

1. Buonocore, E.; Vanoli, L.; Carotenuto, A.; Ulgiati, S. Integrating life cycle assessment and emergy synthesis for the evaluation of a dry steam geothermal power plant in italy. Energy 2015, 86, 476-487. [CrossRef]

2. European Wind Energy Association (EWEA). The Economics of Wind Energy; European Wind Energy Association (EWEA): Brussels, Belgium, 2009.

3. Reboredo, J.C. Is there dependence and systemic risk between oil and renewable energy stock prices? Energy Econ. 2015, 48, 32-45. [CrossRef]

4. Henriques, I.; Sadorsky, P. Oil prices and the stock prices of alternative energy companies. Energy Econ. 2008, 30, 998-1010. [CrossRef]

5. Sadorsky, P. Correlations and volatility spillovers between oil prices and the stock prices of clean energy and technology companies. Energy Econ. 2012, 34, 248-255. [CrossRef]

6. Sadorsky, P. Modeling renewable energy company risk. Energy Policy 2012, 40, 39-48. [CrossRef]

7. Wen, X.; Guo, Y.; Wei, Y.; Huang, D. How do the stock prices of new energy and fossil fuel companies correlate? Evidence from China. Energy Econ. 2014, 41, 63-75. [CrossRef] 
8. Kumar, S.; Managi, S.; Matsuda, A. Stock prices of clean energy firms, oil and carbon markets: A vector autoregressive analysis. Energy Econ. 2012, 34, 215-226. [CrossRef]

9. Gao, Z.K.; Yang, Y.X.; Fang, P.C.; Jin, N.D.; Xia, C.Y.; Hu, L.D. Multi-frequency complex network from time series for uncovering oil-water flow structure. Sci. Rep. 2015, 5. [CrossRef] [PubMed]

10. Reboredo, J.C.; Rivera-Castro, M.A. Wavelet-based evidence of the impact of oil prices on stock returns. Int. Rev. Econ. Financ. 2014, 29, 145-176. [CrossRef]

11. Vacha, L.; Barunik, J. Co-movement of energy commodities revisited: Evidence from wavelet coherence analysis. Energy Econ. 2012, 34, 241-247. [CrossRef]

12. Daubechies, I. Orthonormal bases of compactly supported wavelets. Commun. Pure appl. Math. 1988, 41, 909-996. [CrossRef]

13. Daubechies, I. Ten Lectures on Wavelets; Society for Industrial and Applied Mathematics (SIAM): Philadelphia, PA, USA, 1992; Volume 61.

14. Huang, S.; An, H.; Gao, X.; Huang, X. Time-frequency featured co-movement between the stock and prices of crude oil and gold. Phys. A Stat. Mech. Appl. 2015, 444, 985-995. [CrossRef]

15. Huang, S.; An, H.; Gao, X.; Huang, X. Identifying the multiscale impacts of crude oil price shocks on the stock market in china at the sector level. Phys. A Stat. Mech. Appl. 2015, 434, 13-24. [CrossRef]

16. Huang, X.; An, H.; Gao, X.; Hao, X.; Liu, P. Multiresolution transmission of the correlation modes between bivariate time series based on complex network theory. Phys. Stat. Mech. Appl. 2015, 428, 493-506. [CrossRef]

17. Aguiar-Conraria, L.; Soares, M.J. The continuous wavelet transform: Moving beyond uni- and bivariate analysis. J. Econ. Surv. 2014, 28, 344-375. [CrossRef]

18. Crowley, P.M. A guide to wavelets for economists. J. Econ. Surv. 2007, 21, 207-267. [CrossRef]

19. Jammazi, R. Cross dynamics of oil-stock interactions: A redundant wavelet analysis. Energy 2012, 44, $750-777$. [CrossRef]

20. Jammazi, R.; Aloui, C. Wavelet decomposition and regime shifts: Assessing the effects of crude oil shocks on stock market returns. Energy Policy 2009, 38, 1415-1435. [CrossRef]

21. Jia, X.; An, H.; Fang, W.; Sun, X.; Huang, X. How do correlations of crude oil prices co-move? A grey correlation-based wavelet perspective. Energy Econ. 2015, 49, 588-598. [CrossRef]

22. Gallegati, M. Wavelet analysis of stock returns and aggregate economic activity. Comput. Stat. Data Anal. 2008, 52, 3061-3074. [CrossRef]

23. Gallegati, M. A wavelet-based approach to test for financial market contagion. Comput. Stat. Data Anal. 2012, 56, 3491-3497. [CrossRef]

24. Huang, S.; An, H.; Gao, X.; Hao, X.; Huang, X. The multiscale conformation evolution of the financial time series. Math. Probl. Eng. 2015, 2015, 563145. [CrossRef]

25. Gao, X.Y.; An, H.Z.; Fang, W.; Huang, X.; Li, H.J.; Zhong, W.Q. Characteristics of the transmission of autoregressive sub-patterns in financial time series. Sci. Rep. 2014, 4. [CrossRef] [PubMed]

26. Gao, X.Y.; An, H.Z.; Fang, W.; Huang, X.; Li, H.J.; Zhong, W.Q.; Ding, Y.H. Transmission of linear regression patterns between time series: From relationship in time series to complex networks. Phys. Rev. E 2014, 90. [CrossRef] [PubMed]

27. Gao, Z.-K.; Zhang, X.-W.; Jin, N.-D.; Donner, R.V.; Marwan, N.; Kurths, J. Recurrence networks from multivariate signals for uncovering dynamic transitions of horizontal oil-water stratified flows. EPL 2013, 103. [CrossRef]

28. Gao, Z.K.; Ding, M.S.; Geng, H.; Jin, N.D. Multivariate multiscale entropy analysis of horizontal oil-water two-phase flow. Phys. Stat. Mech. Appl. 2015, 417, 7-17. [CrossRef]

29. Gao, Z.K.; Fang, P.C.; Ding, M.S.; Jin, N.D. Multivariate weighted complex network analysis for characterizing nonlinear dynamic behavior in two-phase flow. Exp. Therm. Fluid Sci. 2015, 60, 157-164. [CrossRef]

30. Lacasa, L.; Luque, B.; Ballesteros, F.; Luque, J.; Nuno, J.C. From time series to complex networks: The visibility graph. Proc. Natl. Acad. Sci. USA 2008, 105, 4972-4975. [CrossRef] [PubMed]

31. Zanin, M.; Sousa, P.; Papo, D.; Bajo, R.; García-Prieto, J.; Del, P.F.; Menasalvas, E.; Boccaletti, S. Optimizing functional network representation of multivariate time series. Sci. Rep. 2012, 2, 630. [CrossRef] [PubMed]

32. Marwan, N.; Donges, J.F.; Zou, Y.; Donner, R.V.; Kurths, J. Complex network approach for recurrence analysis of time series. Phys. Lett. A 2009, 373, 4246-4254. [CrossRef]

33. Donner, R.V.; Small, M.; Donges, J.F.; Marwan, N.; Zou, Y.; Xiang, R.; Kurths, J. Recurrence-based time series analysis by means of complex network methods. Int. J. Bifurc. Chaos 2011, 21, 1019-1046. [CrossRef] 
34. Xu, X.; Zhang, J.; Small, M. Superfamily phenomena and motifs of networks induced from time series. Proc. Natl. Acad. Sci. USA 2008, 105, 19601-19605. [CrossRef] [PubMed]

35. Kilian, L. The impact of the shale oil revolution on us oil and gasoline prices. Available online: http: / / papers.ssrn.com/sol3/papers.cfm?abstract_id=2538422 (accessed on 31 May 2016).

36. Deng, J. Introduction to grey mathematical resources. J. Grey Syst. 2008, 20, 87-92.

37. Deng, J.L. Control problems of grey systems. Syst. Control. Lett. 1982, 1, 288-294.

38. Chang, T.C.; Lin, S.J. Grey relation analysis of carbon dioxide emissions from industrial production and energy uses in taiwan. J. Environ. Manag. 1999, 56, 247-257. [CrossRef]

39. Torrence, C.; Compo, G.P. A practical guide to wavelet analysis. Bull. Am. Meteorol. soc. 1998, 79, 61-78. [CrossRef]

40. Grinsted, A.; Moore, J.C.; Jevrejeva, S. Application of the cross wavelet transform and wavelet coherence to geophysical time series. Nonlinear Process. Geophys. 2004, 11, 561-566. [CrossRef]

41. Blondel, V.D.; Guillaume, J.L.; Lambiotte, R.; Lefebvre, E. Fast unfolding of community hierarchies in large networks. J. Stat. Mech. 2008. [CrossRef]

(C) 2016 by the authors; licensee MDPI, Basel, Switzerland. This article is an open access article distributed under the terms and conditions of the Creative Commons Attribution (CC-BY) license (http:/ / creativecommons.org/licenses/by/4.0/). 